02

\title{
Оптические спектры гамма-облученных кристаллов LiF с анизотропными наночастицами лития
}

\author{
(C) М.А. Муссаева, Э.М. Ибрагимова, Ш.Н. Бузриков \\ Институт ядерной фризики АН Республики Узбексистан, \\ 100214 Ташкент, Узбекистан \\ e-mail: ibragimova@inp.uz, mussaeva@inp.uz
}

Поступила в редакцию 14.12.2017 г.

Исследован оптический отклик анизотропных дефектов и наночастиц $\mathrm{Li}$ с трех сторон кристаллов $\mathrm{LiF}$ в виде куба со стороной $10 \mathrm{~mm}$, облученных ${ }^{60} \mathrm{Co}$ гамма-лучами в интервале доз $10^{5}-10^{9} \mathrm{R}$ при $320 \mathrm{~K}$ на воздухе. С помощью сканирующего электронного микроскопа после максимальной дозы $10^{9} \mathrm{R}$ обнаружены субмикронные чешуйки металлического лития, упорядоченные в длинные параллельные нанонити. Резонансное поглощение, которое смещается в пределах $272-295 \mathrm{~nm}$ с ростом дозы, приписывается наноколлоидам лития, которые расположены в плоскости (110). Видимая только на грани (100) полоса $202-225 \mathrm{~nm}$ сужается при дозах $<10^{5} \mathrm{R}$ и приписана двухатомным молекулам фтора в междоузлиях. Появление триплетов 209-212-215 nm при $2.7 \cdot 10^{5} \mathrm{R}$ на грани $(100)$ и $211-213-215 \mathrm{~nm}$ при $0.9 \cdot 10^{5} \mathrm{R}$ на (010) связано с радиационно-индуцированными аксиально-симметричными биполяронами с большой силой осциллятора. Триплетное расщепление полосы $445 \mathrm{~nm}$ в виде $438-445-450 \mathrm{~nm}$ видно только на (010) после $10^{6} \mathrm{R}$ и связано с поверхностными плазмонными поляритонами (продольным и поперечным) вытянутой наночастицы Li. Комплексы $\left(\mathrm{F}_{2}-\mathrm{F}_{3}\right)$ ориентированы в самой дефектной плоскости $(111)$ и видны по трем осям куба.

DOI: $10.21883 /$ OS.2018.05.45940.293-17

\section{1. Введение}

Применение соединений лития в современных супераккумуляторах обусловлено высоким электродным потенциалом $-3.06 \mathrm{~V}$, высокой подвижностью ионов лития $\mathrm{Li}^{1+}$ и большой плотностью электронов $\left(4.7 \cdot 10^{22} \mathrm{~cm}^{-3}\right)$. Известно, что при больших дозах облучения ионных щелочно-галоидных кристаллов образуются нейтральные и заряженные дивакансии и тривакансии галогена, которые скапливаются в виде коллоидных частиц металла с размерами от 5 до $100 \mathrm{~nm}$ в зависимости от энергии и дозы облучения [1]. Отмечено, что при последующей термообработке эти коллоиды вырастают до $1 \mu \mathrm{m}$. Было также обнаружено в лауэграммах, что при больших дозах размерные радиационные дефекты упорядочиваются [1].

Электронная микроскопия вытравленных поверхностей облученных нейтронами кристаллов $\mathrm{LiF}$ выявила декорирование дислокаций скоплениями радиационных дефектов с размерами от 10 до $100 \mathrm{~nm} \mathrm{[2].} \mathrm{Было}$ обнаружено, что при малых дозах быстрых и тепловых нейтронов $\sim 10^{17} \mathrm{n} / \mathrm{cm}^{2}$ точечные дефекты образуются в структуре монокристаллов $\mathrm{LiF}$ беспорядочно, а при больших дозах они располагаются в виде упорядоченной дефектной структуры [3]. Позднее авторы [4] исследовали образование металлических наночастиц лития и их оптические характеристики после высокодозного $\left(5 \cdot 10^{8} \mathrm{R}\right)$ гамма-облучения кристаллов $\mathrm{LiF}$ толщиной $0.3 \mathrm{~mm}$ и последующего отжига при 600-650 К. Обнаружены с помощью атомно-силового микроскопа хаотично расположенные выпуклости, обусловленные наночасти- цами лития размерами от 10 до $30 \mathrm{~nm}$, которым авторы приписывают полосу поглощения с максимумом вблизи $290 \mathrm{~nm}$ (не отделенную от полосы $F$-центра $250 \mathrm{~nm}$ ).

Нами было показано методом рентгеновской дифракции, что в процессе радиолиза (доза $10^{8} \mathrm{R}$ облучения источником ${ }^{60}$ Со гамма-квантов $\sim 1.25 \mathrm{MeV}$ при $765 \mathrm{R} / \mathrm{s}$ в воде) развивается двойникование кристаллической решетки в $\mathrm{LiF}$ с ориентацией 100 и образуются нанокристаллиты $\mathrm{LiOH}$ (рефлекс 112) со средним размером $28 \mathrm{~nm}$ [5]. Далее нами исследована электропроводность в интервале температур 190-400 K в кристаллах LiF до и после облучения при $300 \mathrm{~K}$ в интервале доз $7.8 \cdot 10^{5}-10^{8} \mathrm{R}$ при $406 \mathrm{R} / \mathrm{s}$ [6]. Только после облучения обнаружена характерная скачкообразная проводимость по локализованным состояниям с пиком около $300 \mathrm{~K}$, когда образуются агрегаты 2 и более электронных $F$-центров и наноколлоиды Li $[1,4-9]$. Нами было показано, что образование 2 агрегатов $F$-центров приводит к расщеплению полосы $250 \mathrm{~nm}$, а образование 4 агрегатов $F$-центров приводит к расщеплению полосы $445 \mathrm{~nm}$ и появлению слабых широких полос $320,380 \mathrm{~nm}$ и нестабильных полос 500-650 nm. Узкий поперечный резонанс $210 \mathrm{~nm}$ и продольный резонанс 270-300 nm приписан плоским наночастицам $\mathrm{Li}_{5}$ размером $5 \mathrm{~nm}$, вырастающим до наностержней $>8 \mathrm{~nm}$, образующихся вокруг примеси меди $[8,9]$.

В работе [10] показано, что поглощающая способность фотона, возбуждающего и плазмон, и внутризонный переход в полубесконечном электронном газе с металлической плотностью, составляет около $10^{13} \mathrm{~s}^{-1}$ в УФ области примерно $h \omega_{p}+\epsilon_{\mathrm{F}}$. Плазмонное поглощение ока- 


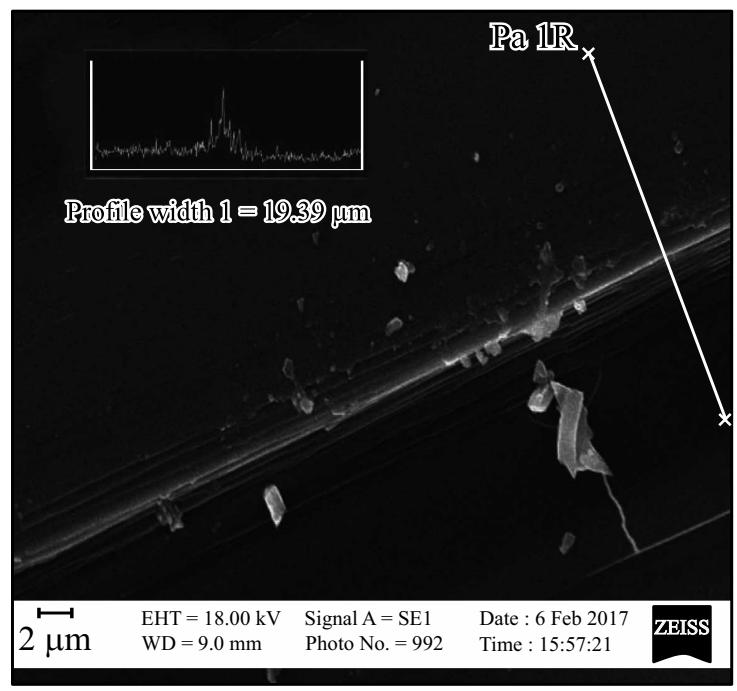

$b$

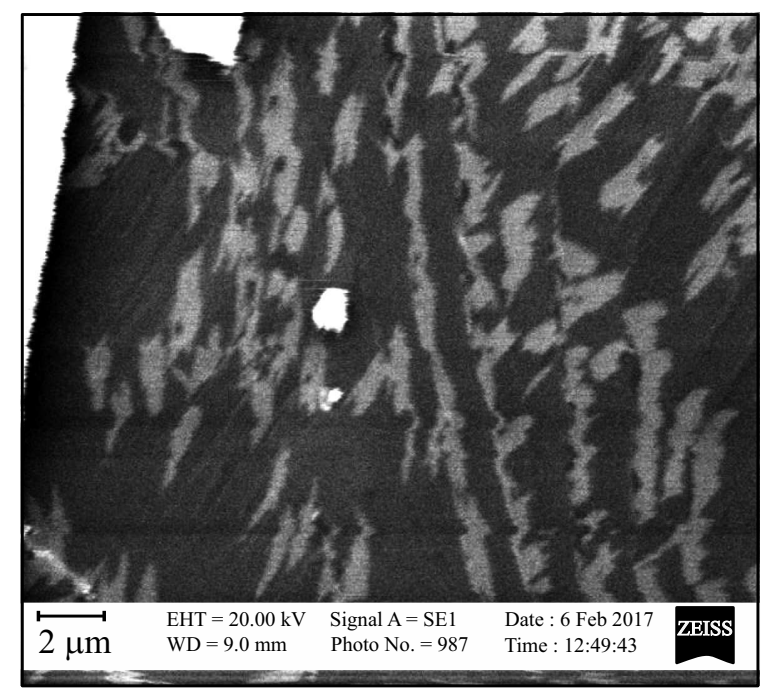

Рис. 1. Микрофотографии поверхностей скола кристаллов $\operatorname{LiF}-$ необлученного (a) и облученного гамма-лучами дозой $1000 \mathrm{MR}(b)$.

зывается дает только малый вклад в спектр УФ поглощения большинства металлов, за исключением щелочных металлов, у которых плазмонный вклад того же порядка, что и межзонное поглощение. Линейная суперпозиция Друде межзонной и плазмонной проводимостей позволяет предположить, что натрий и калий могут давать слабые широкие полосы поглощения соответственно около 8.8 и $5.8 \mathrm{eV}$ из-за возбуждений плазмонов (можно экстраполировать плазмон для лития до $12 \mathrm{eV}$ ). Авторы рассчитали плазмонное поглощение в УФ области для металлов с квазисвободными электронами.

В монографии [11], посвященной наноплазмонике, дано систематическое описание свойств плазмонных колебаний коллоидов и наночастиц металлов в жидкой среде. Коллоиды лития приготавливали в парафине, затем растворяли в бензине и снимали спектры поглощения [12]. Расчет поглощения сферических наночастиц по теории Друде позволил авторам определить связь между размерами коллоидов и максимумом полосы поглощения. Учет эллиптичности формы коллоида привел к расщеплению расчетной полосы поглощения, что подтверждается экспериментально. Однако наблюдение плазмонов от наночастиц металла в твердом диэлектрике практически отсутствует в литературе.

Цель работы - выявление анизотропии оптического поглощения несферических, вытянутых (квазиодномерных) металлических наночастиц в кристаллах LiF после гамма-облучения.

\section{2. Объект и методы исследований}

Были выбраны монокристаллы LiF высокого качества для детекторов. С помощью рентгено-флюоресцентного анализа определен примесный состав образцов: $\mathrm{Cu}-$
$0.02 \%$, а также $\mathrm{Ti}, \mathrm{V}, \mathrm{Cr}, \mathrm{Mn}, \mathrm{As}, \mathrm{Au}, \mathrm{Br}$ в количестве $<0.01 \%$. Для выяснения анизотропии поверхностных состояний и формы наночастиц Li образцы откалывали от большого кристалла в виде кубиков с площадью граней $15 \times 15 \mathrm{~mm}$ по кристаллографической плоскости (100) и $15 \times 10 \mathrm{~mm}$. Облучение проводили на радиоизотопном источнике гамма-излучения ${ }^{60} \mathrm{Co}$ с мощностью дозы $510 \mathrm{R} / \mathrm{s}$ в интервале доз $10^{5}-10^{7} \mathrm{R}$ при $320 \mathrm{~K}$ в воздушной среде.

Спектры оптического поглощения каждого образца измеряли со всех трех граней $a, b, c$ на спектрофотометре СФ-56 в интервале $190-1100 \mathrm{~nm}$ в режиме для сильно поглощающих объектов с оптической плотностью до 5. Спектры снимали через $30 \mathrm{~min}$ после каждого этапа облучения, чтобы увидеть нестабильные центры и динамику релаксации пространственного заряда комптон-электронов, создаваемого в ионном кристалле $\mathrm{LiF}$ гамма-квантами с энергиями 1.17 и $1.32 \mathrm{MeV}$. Идентификацию полос или линий от точечных, агрегатных и коллоидных центров проводили в соответствии с вышеприведенными литературными данными [1-12].

\section{3. Результаты исследований}

На рис. $1, a, b$ показаны микрофотографии (снятые при одинаковом увеличении на сканирующем электронном микроскопе EVOMA10, Zeiss) поверхностей скола кристаллов $\mathrm{LiF}$ необлученного $(a)$ и облученного гаммалучами дозой $10^{9} \mathrm{R}(b)$, покрытых нанослоями графита толщиной $30-40 \mathrm{~nm}$ для удаления заряда, накапливающегося на поверхности диэлектрика. На вставке рис. 1, $a$ показан измеренный профиль скола необлученного кристалла вдоль линии $\mathrm{Pa}-1 \mathrm{R}$. 

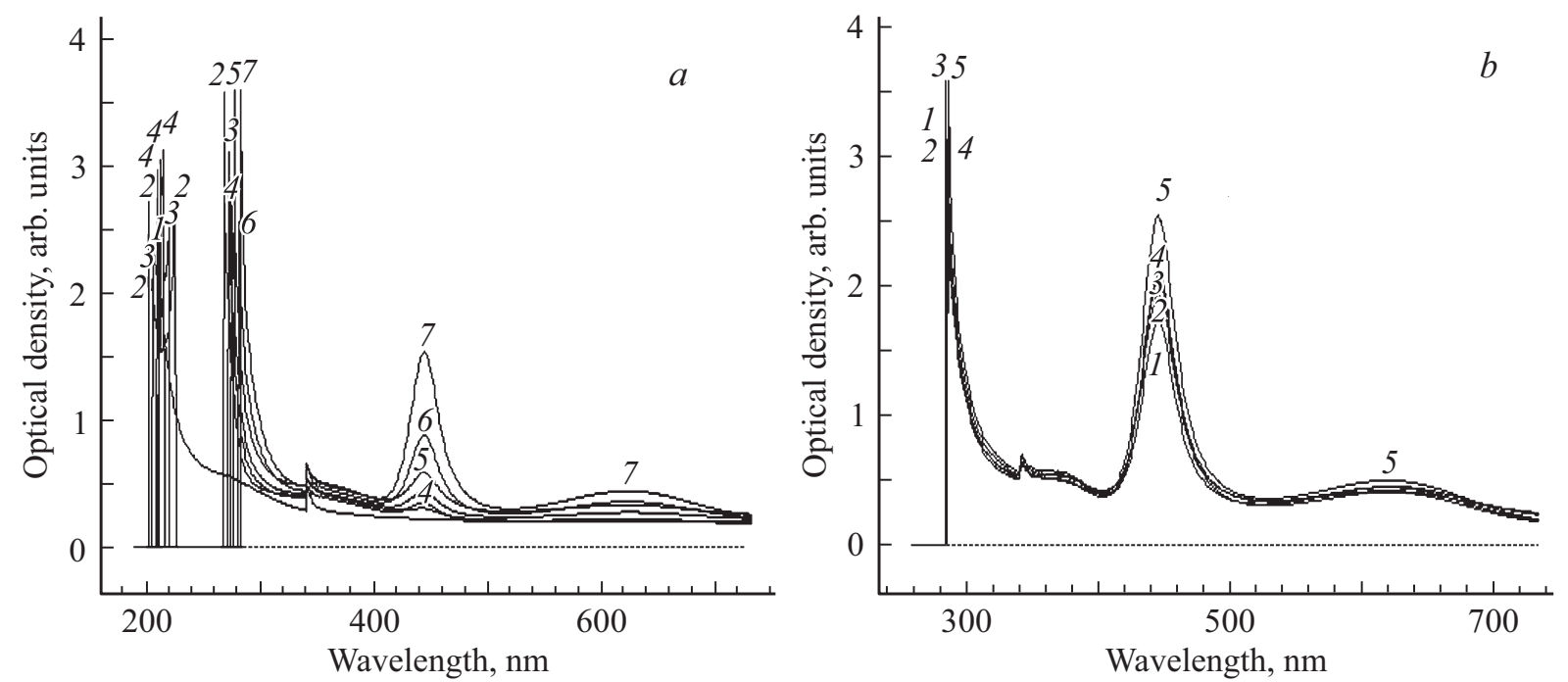

Pис. 2. Спектры оптического поглощения $\mathrm{LiF}$, снятые с грани (100): (a) необлученный (1), облученный последовательно дозами $0.9 \cdot 10^{5}(2), 1.8 \cdot 10^{5}(3), 2.7 \cdot 10^{5}(4), 3.6 \cdot 10^{5}(5), 5.4 \cdot 10^{5}(6), 7.2 \cdot 10^{5} \mathrm{R}(7) ;(b)$ облученный последовательно дозами $9.1 \cdot 10^{5}(1), 1.1 \cdot 10^{6}(2), 1.28 \cdot 10^{6}(3), 1.46 \cdot 10^{6}(4), 1.65 \cdot 10^{6} \mathrm{R}(5)$.
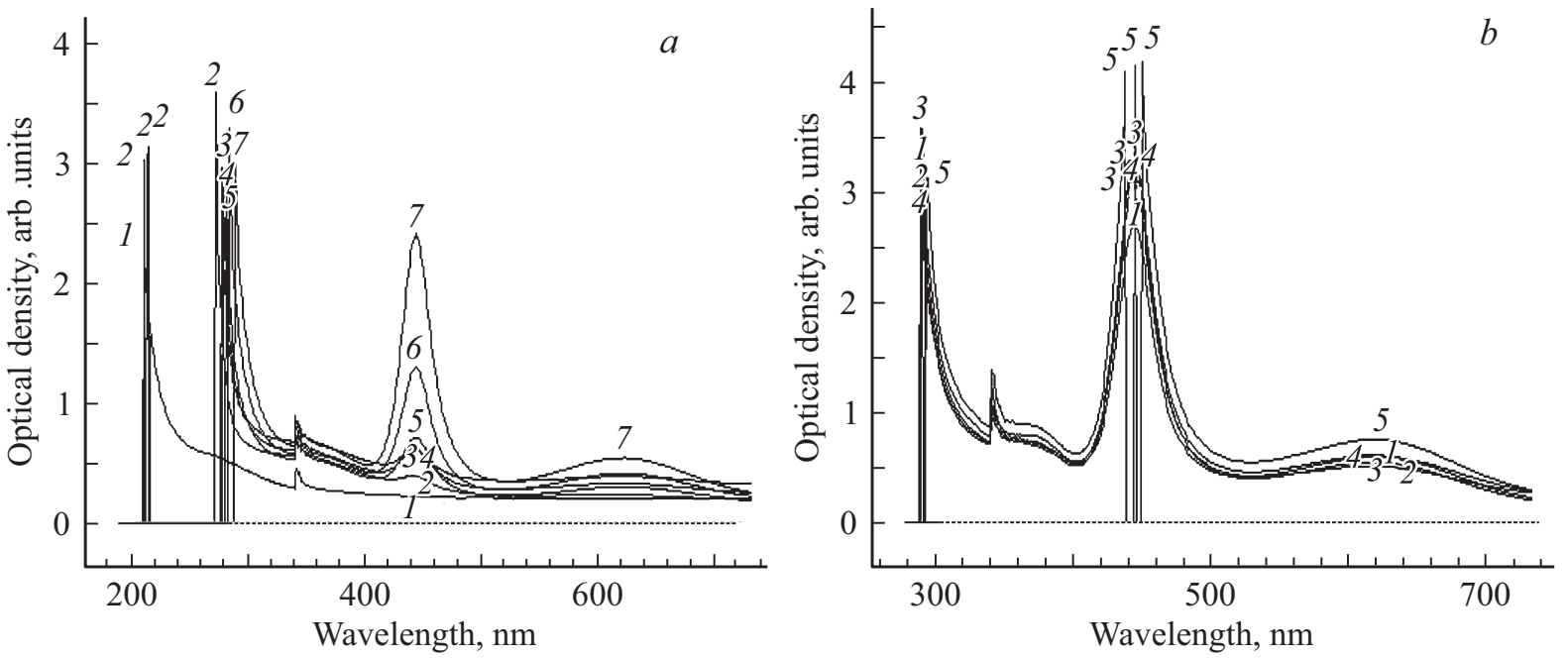

Рис. 3. Те же спектры, что на рис. 2, снятые с грани (010).

Из-за очень малой атомной массы лития (практически за пределами возможности рентгеновского детектора в электронном микроскопе, который подтвердил наличие только фтора) понадобилась максимально доступная высокая доза гамма-излучения $10^{9} \mathrm{R}$, чтобы суметь увидеть только под разрывом нанопленки графита наиболее крупные агрегаты наночастиц металлического лития в виде ярких упорядоченных субмикронных чешуек с электронной плотностью, более высокой, чем диэлектрическая матрица кристалла LiF. Параллельные нанонити расположены с интервалом около $1 \mu \mathrm{m}$ и могут достигать длины $100 \mu \mathrm{m}$. Полученная поверхностная наноструктура качественно подтверждает результаты, полученные Колонцовой при помощи растрового микроскопа в Институте кристаллографии РАН на тонких пластинках LiF: упорядоченное расположение вытянутых микрообъектов, предположительно приписанных металлическому литию на основании яркого изображения на темно-сером фоне поверхности [3], а также результаты Брюквиной, полученные на сканирующем мультимикроскопе СММ-2000: протяженные плоские пластины от 300 до $2000 \mathrm{~nm} \mathrm{[4].}$

На рис. 2 и 3 приведены спектры оптического поглощения кристаллов $\mathrm{LiF}$, снятые по осям $a$ и $b$ куба со сторонами $10 \mathrm{~mm}$ до и после гамма-облучения дозами от $0.9 \cdot 10^{5} \mathrm{R}$ до $1.65 \cdot 10^{6} \mathrm{R}$, когда быстро растет число $M$-центров $(450 \mathrm{~nm})$ и $F_{2}^{+}(\sim 620 \mathrm{~nm})$, у которых образуются наноколлоиды $\mathrm{Li}(380 \mathrm{~nm})[5,9]$. На рис. 2, $a$ нами впервые обнаружено сужение полосы 202-225 nm при малых дозах до расщепления на дублеты (спектры 2 и 3), которые видны только на грани (100), что позволяет приписать ее аксиально симметричной 

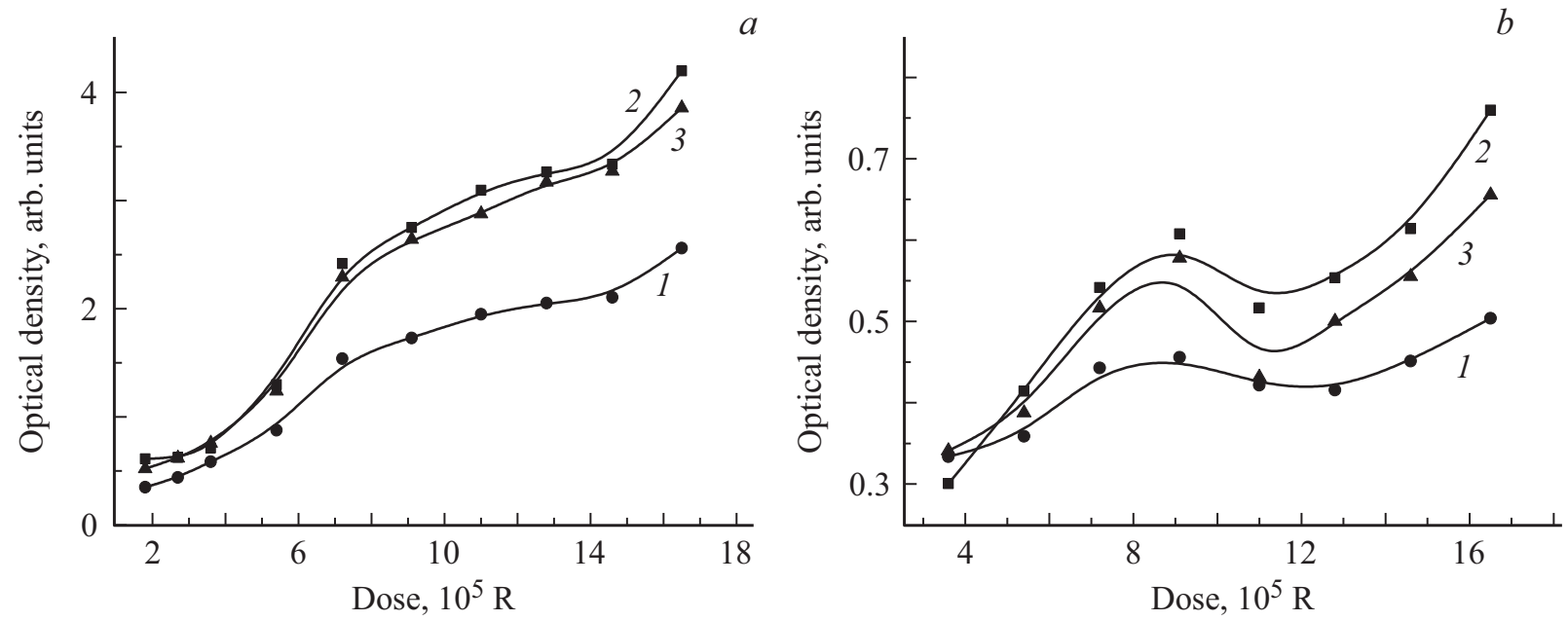

Рис. 4. Дозовое накопление центров окраски по спектрам, снятым с трех граней куба LiF: (100) (1), (010) (2), (001) (3). (a) $М$-полоса $450 \mathrm{~nm},\left(\right.$ b) $F_{2}^{+}$-полоса $620 \mathrm{~nm}$.

двухатомной молекуле межузельного фтора. Появление триплетов 209-212-215 $\mathrm{nm}$ при $2.7 \cdot 10^{5} \mathrm{R}$ на грани (100) и $211-213-215 \mathrm{~nm}$ при $0.9 \cdot 10^{5} \mathrm{R}$ на $(010)$ связано с радиационно-индуцированными аксиальносимметричными биполяронами с большой силой осциллятора и поэтому с очень интенсивным поглощением. Резонанс при $270 \mathrm{~nm}$, появляющийся после минимальной дозы, с ростом дозы смещается до $284 \mathrm{~nm}$ (рис. 2, $a$, спектры 2-7) и далее до $286 \mathrm{~nm}$ (рис. 2, $b$, спектры $1-5)$, приписывается наноколлоидам лития. При дозе $7.2 \cdot 10^{5} \mathrm{R}$ красное смещение края зоны до $284 \mathrm{~nm}$ прекратилось, одновременно начинается быстрый рост полосы $445 \mathrm{~nm}$, связанной с $M$-центрами, и появляется нестабильная полоса $620 \mathrm{~nm}$, связанная с заряженными $F_{2}^{+}$-центрами.

На рис. 3,a виден триплет 211-213-215 nm (спектр 2), а затем смещение резонанса от 272 до $295 \mathrm{~nm}$ (рис. 3), как и на рис. 2. То есть наноколлоиды лития расположены в плоскости (110), видной как проекции на гранях (100) и (010). Только на рис. $3, b$ видно триплетное расщепление полосы $450 \mathrm{~nm}$ на 438-445-450 nm после набора максимальной дозы $1.65 \cdot 10^{6} \mathrm{R}$. Триплет и слабая полоса $620 \mathrm{~nm}$ нестабильны, зависят от ориентации, но оптическая плотность изотропна (при снятии спектров по всем граням куба), т. е. комплексы $\left(F_{2}-F_{3}\right)$ ориентированы в самой дефектной плоскости (111), проекции которой видны по трем осям. Расщепление связано с продольными и поперечными поверхностными плазмонными поляритонами на наночастицах. Чем выше анизотропия наночастицы $\mathrm{Li}$, вытянутой по (111), тем больше разность их частот. Энергетически выгодно образование заряженных $F_{n^{-}}$и $n \mathrm{Li}$-дефектных комплексов на вершинах упорядоченных двойников.

Короткоживущие полосы поглощения наблюдались в области $4.75-5.5 \mathrm{eV}(225-260 \mathrm{~nm})$ в температурном интервале $11-150 \mathrm{~K}$ и временном интервале $10^{-8}-10 \mathrm{~s}$ после облучения $\mathrm{LiF}$ импульсами $350 \mathrm{keV}$ электронов и приписывались триплет-триплетным переходам автолокализованных экситонов с точечной симметрией $D_{2 h}$ и ориентациями $\{110\}$ и $\{111\}$ [13]. Лобанов рассчитал расщепление полосы $F$-центра $250 \mathrm{~nm}$ на дублет 220 и $270 \mathrm{~nm}$ при сближении соседних $F$-центров на расстояние менее $20 \mathrm{~nm}$, соответствующее радиусу экситона $\mathrm{Li}$ в межузельном положении относительно вакансий фтоpa [14]. Эти значения находятся в хорошем согласии с экспериментально обнаруженным нами расщеплением (рис. 2 и 3) и соответствующей дозой облучения.

На рис. 4 приведены дозовые зависимости накопления центров окраски в единицах оптической плотности кристаллов $\mathrm{LiF}$, снятые по трем осям куба: (a) $M$-полоса $450 \mathrm{~nm},(b) F_{2}^{+}$-полоса $620 \mathrm{~nm}$ после гамма-облучения дозами от $0.9 \cdot 10^{5}$ до $1.65 \cdot 10^{6} \mathrm{R}$. Видно, что зависимости $M$-центров по осям $a, b$ (рис. $4, a$, кривые 2 и 3) практически совпадают, а по оси $c$ (кривая 1 ) зависимость заметно слабее. Это подтверждает, что ось парного $F-F$-центра направлена по $\{110\}$. Но зависимости для $F_{2}^{+}$-центров по всем осям различаются, т.е. эти центры характеризуются трехосным эллипсоидом $\{111\}$.

\section{4. Выводы}

При изотропном гамма-облучении кристалла LiF кубической симметрии возникает анизотропия оптического поглощения из-за вытянутой формы агрегатных центров. Резонансное поглощение, изменяющееся в пределах 272-295 nm с ростом дозы, приписывается наноколлоидам $\mathrm{Li}$, расположенным в плоскости (110), размеры которых растут с дозой облучения. Узкие триплеты 209-212-215 и 211-213-215 nm на гранях (100) и (010) связаны с радиационноиндуцированными аксиально-симметричными биполяронами с большой силой осциллятора в плоскости (110). 
Упорядоченное расположение наночастиц Li на поверхности гамма-облученного $\mathrm{LiF}$ в виде длинных параллельных нитей объясняет его нелинейно-оптические свойства LiF [1,4-6].

Работа выполнена при поддержке грантом ОТ-Ф2-26 Агентства по науке и технологиям Республики Узбекистан.

\section{Список литературы}

[1] Siscafus K.E., Kotomin E.A. Radiation Effects in Solids. Amsterdam: Uberuaga Springer B. P., 2007. Ch. 7.

[2] Зефирова В.Л., Колонцова Е.В., Телегина И.В. // ДАН CCCP. 1971. T. 199. C. 821

[3] Колонцова Е.В., Телегина И.В., Зефирова В.Л. Радиационные эффекты в твердых телах. Киев: Наукова думка, 1977. C. 102,158

[4] Брюквина Л.И., Мартынович Е.Ф. // ФТТ. 2012. Т. 54. Вып. 12. С. 2056.

[5] Муссаева М.А., Ибрагимова Э.М., Каланов М.У., Муминов М.И. // ФТТ. 2006. Т. 48. Вып. 12. C. 2170. Mussaeva M.A., Ibragimova E.M., Kalanov M.U., Muminov M.I. // Phys. Sol. St. 2006. V. 48. N 12. P. 2295. doi $10.1134 / \mathrm{S} 1063783406120092$

[6] Муссаева М.А., Сандалов В.Н., Ибрагимова Э.М. // Докл. АН РУз. 2013. N 2. C. 22.

[7] Lushchik A., Lushchik Ch., Shwartz K., Vasilchenko E., Papaleo R., Sorokin M., Volkov A.E., Neumann R., Trautmann C. // Phys. Rev. B. 2007. V. 76. P. 054114.

[8] Муссаева М.А., Ибрагимова Э.М., Бузриков Ш.Н. // Докл. АН РУз. 2011. N 1. C. 29.

[9] Ibragimova E.M., Mussaeva M.A., Kalanov M.U., Mukhamedshina N.M., Sandalov V.N. // J. Phys. Conf. Ser. 2012. V. 391. P. 012172. doi 10.1088/1742-6596/391/1/012172

[10] Esposito R.J., Muldawer L., Bloomfield P.E. // Phys. Rev. 1968. V. 168. P. 744.

[11] Климов В.В. Наноплазмоника. М.: Физматлит, 2009. 480 с.

[12] Назаренко В.Н., Нестеренко О.В., Радченко И.С., Степанкина И.Б. // Восточно-Европейский журнал передовых технологий. 2013. Т. 3/5 (63). С. 8.

[13] Лисицына Л.А., Гречкина Т.В., Корепанов В.И., Лисицын В.М. // ФТТ. 2001. Т. 43. Вып. 9. С. 1613.

[14] Лобанов Б.Д., Костюков В.М., Максимова Н.Т., Саломатов В.Н., Щепина Л.И., Юрьева Т.Г. // ФТТ. 1995. Т. 37. Вып. 9. С. 2545. 